\author{
Jörg Scheinfeld
}

\title{
Organtransplantation und Strafrechtspaternalismus
}

Eine Analyse der strafbewehrten Spendebegrenzungen im deutschen Transplantationsrecht

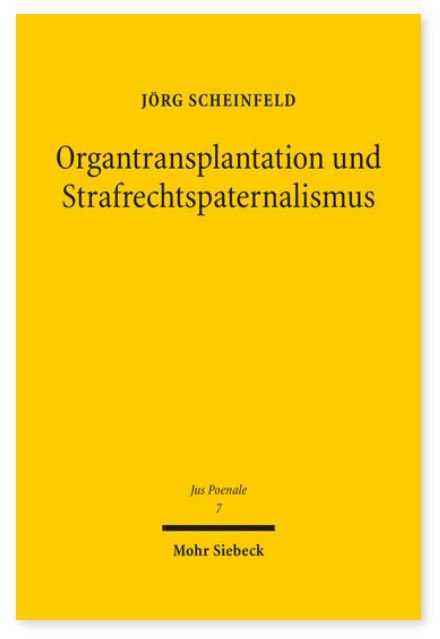

2016. XXI, 617 Seiten. JusPoen 7

ISBN 978-3-16-153393-8

DOI 10.1628/978-3-16-153393-8

eBook PDF 134,00€

ISBN 978-3-16-153392-1

Leinen $134,00 €$
Das deutsche Recht kennt fürsorglich gemeinte Verbote, die den Bürger davor schützen sollen, sich selbst zu schädigen. In diesem Geiste agierend lässt sich der deutsche Gesetzgeber im Recht der Organtransplantation selbst von der dramatischen Organknappheit nicht abhalten, vollverantwortlichen Akteuren enge Grenzen für gesundheits- und lebensrettende Organspenden zu ziehen und Überschreitungen dieser Grenzen - auch wenn mit bester Absicht begangen - sogar zu bestrafen. Jörg Scheinfeld hinterfragt die Berechtigung dieser Strafnormen: de lege lata auf den Ebenen des Straf- und Verfassungsrechts sowie de lege ferenda auf dem Feld der Rechtsethik. Bezogen auf die Spende von Organen im engeren Sinn macht Jörg Scheinfeld die mit dem geltenden Strafrechtspaternalismus verfolgten Zwecke sichtbar und misst sie an den grundlegenden Prinzipien des Strafrechts.

Jörg Scheinfeld Geboren 1970; Studium der Rechtswissenschaften an der Ruhr-Universität Bochum; 2005 Promotion; 2012 Habilitation; seitdem Lehrstuhlvertreter und später Lehrkraft für besondere Aufgaben an der Universität Mainz.
Jetzt bestellen:

https://mohrsiebeck.com/buch/organtransplantation-und-strafrechtspaternalismus-9783161533938?no_cache=1 order@mohrsiebeck.com

Telefon: +49 (0)7071-923-17

Telefax: +49(0)7071-51104 